\title{
Sedation during Minimal Invasive Surfactant Therapy in Preterm Infants
}

\author{
Janneke Dekker Enrico Lopriore Monique Rijken Esther Rijntjes-Jacobs \\ Vivianne Smits-Wintjens Arjan te Pas \\ Division of Neonatology, Department of Pediatrics, Leiden University Medical Center, Leiden, The Netherlands
}

\section{Key Words}

Comfort · Minimally invasive surfactant therapy $\cdot$ Preterm infant $\cdot$ Sedation

\begin{abstract}
Background: There is no data available whether sedation should be given during minimally invasive surfactant therapy (MIST). Objective: To compare the level of comfort of preterm infants receiving sedation versus no sedation for MIST. Methods: A retrospective study of preterm infants receiving MIST was performed in Leiden University Medical Center in 2014. Sedation (propofol $1 \mathrm{mg} / \mathrm{kg}$ ) was optional and left to the discretion of the caregiver. Standardized COMFORTneo scores were compared, and COMFORTneo $<14$ was considered comfortable. Basic characteristics and complications were noted. Results: In 38 infants receiving MIST, 23 received propofol and 15 were not sedated. Mean (SD) gestational age [29 (2) vs. 29 (3) weeks] and birth weight [1,312 (483) vs. 1,469 (588) g] were not different. Median (IQR) COMFORTneo was not different between the groups before [11 (9-15) vs. $10(8-12)]$ and after MIST [10 (8-12) vs. $9(8-10)]$, but lower in the sedated group during MIST [12 (9-17) vs. $20(15-23)]$ with more often COMFORTneo $<14$ ( 56 vs. $11 \%$ ). Duration of MIST [2 (2-4) vs. 3 (2-7) min] and occurrence of bradycardia (13 vs. $33 \%$ ) and hypotension ( 21 vs. $18 \%$ ) were not different.
\end{abstract}

\section{KARGER}

E-Mail karger@karger.com www.karger.com/neo

\section{C) 2016 The Author(s) \\ Published by S. Karger AG, Basel 1661-7800/16/1094-0308\$39.50/0} This article is licensed under the Creative Commons Attribution-
NonCommercial-NoDerivatives 4.0 International License (CC BYNC-ND) (http://www.karger.com/Services/OpenAccessLicense) Usage and distribution for commercial purposes as well as any distribution of modified material requires written permission.
Although not significant, intubation occurred more often in the sedated group (during MIST: 9 vs. $0 \%,<24 \mathrm{~h}$ after MIST: 26 vs. $13 \%$ ). During MIST, oxygen saturation $<80 \%$ lasted longer in the sedated group [3 (2-4) vs. 1 (0-2) min], and nasal intermittent positive pressure ventilation was applied more (100 vs. $33 \%)$. Conclusions: Preterm infants receiving MIST were more comfortable when sedation was given, but needed ventilation more often. A randomized controlled trial is warranted to test whether the benefit of sedation outweighs the risks of complications.

(C) 2016 The Author(s)

Published by S. Karger AG, Basel

\section{Background}

Many preterm infants need surfactant therapy to diminish alveolar surface tension and work of breathing caused by respiratory distress syndrome, so as to avoid the occurrence of atelectasis [1]. While intubation and mechanical ventilation is increasingly being avoided $[2$, $3]$, infants are still being intubated and mechanically ventilated for surfactant therapy [4]. Mechanical ventilation can, however, lead to lung injury and ultimately to bronchopulmonary dysplasia [5]. The incidence of bronchopulmonary dysplasia decreases when noninvasive ventilation increases [6]. In this context, minimally invasive 
surfactant therapy (MIST) techniques are promising, in which surfactant is administered to a spontaneously breathing infant who then remains on continuous positive airway pressure [7-9]. During MIST, the vocal cords are visualized by the use of a laryngoscope and the trachea is catheterized using a semirigid catheter, and then the surfactant is instilled [4]. To date, most neonatal intensive care units (NICUs) in the Netherlands have adopted this procedure.

There is consensus that an endotracheal intubation procedure should be performed while the infant is adequately sedated $[10,11]$. However, there is an ongoing debate whether or not sedation should be used during MIST as the presence of spontaneous breathing is a prerequisite for the procedure. So far, there are no studies concerning sedation during this procedure. In the recent published studies and current trials on MIST, no sedation is given before MIST [4].

By using a laryngoscope during MIST, pharyngeal stretching triggers sympathetic and parasympathetic reflexes, which could lead to cardiovascular responses [11]. Also, when the infant is not sedated, efforts to resist the laryngoscope and attempts to cry can cause an increase in intracranial pressure, which could result in impairment of the venous return of the brain and intracranial venous hypertension $[10,12,13]$. This can then contribute to the risk of intraventricular hemorrhage [10]. In addition, laryngoscopy is associated with apnea, increased blood pressure, decreased heart rate and decreased transcutaneous $\mathrm{PO}_{2}$ [14-16]. These differences in vital signs were greater in infants who did not receive any premedication [16]. However, many analgesic agents used for neonatal intubation have been studied, and side effects such as respiratory depression, hypotension, muscle rigidity, increased intracranial blood pressure and decreased cerebral blood flow have been reported $[17,18]$.

Propofol is routinely used as premedication for endotracheal intubation at our center. Although the maintenance of spontaneous breathing is described as an advantage of propofol, hypotension and respiratory depression have been reported [18].

The use of propofol during MIST is currently left to the discretion of the attending neonatologist when discomfort is anticipated. Propofol may then contribute to more comfort and less resistance from the infant during the procedure, which can increase the success of the procedure. However, administering propofol could also cause respiratory depression and increase the chance for noninvasive intermittent positive pressure ventilation or, when respiratory depression persists, intubation and me- chanical ventilation. There is no data available whether the use of propofol for more comfort during MIST outweighs the risk of failure of the procedure and the occurrence of complications.

We performed a cohort study to compare the level of comfort and the occurrence of complications of infants receiving sedation with infants receiving no premedication during MIST.

\section{Materials and Methods}

A retrospective cohort study was conducted at the neonatal department of the Leiden University Medical Center. All admitted infants receiving surfactant by MIST in the year 2014 were included in this study. We only included the first MIST, repeated surfactant doses by MIST were excluded. The criteria for receiving surfactant by MIST were: gestational age $25+6$ to $36+6$ weeks of gestation, no need for imminent intubation, adequate respiratory drive, continuous positive airway pressure level $\geq 8 \mathrm{~cm} \mathrm{H}_{2} \mathrm{O}$ and $\mathrm{FiO}_{2}>0.3$.

According to the local protocol the decision whether to give sedation for MIST was left to the discretion of the attending neonatologist. For endotracheal intubation, intravenous propofol 2.5 $\mathrm{mg} / \mathrm{kg}$ is standardly used for sedation in our unit. However, to maintain spontaneous breathing and reduce the risk of side effects, a reduced dose of intravenous propofol $(1 \mathrm{mg} / \mathrm{kg})$ was administered before MIST. In each infant, nonpharmacological techniques for comfort were also performed, which consisted of the administration of oral sucrose $24 \%$ in the cheek pouch of the infant along with a pacifier at least 2 min before the procedure, and swaddling the infant in a swaddling cloth to keep the infant contained.

MIST was performed using the method as described earlier by Dargaville et al. [8], in which the vocal cords are visualized using a laryngoscope, and then a semirigid angiocatheter is orally introduced to catheterize the trachea.

The infants receiving propofol (sedated group) were compared with the infants without premedication (nonsedated group). Nurses in our unit routinely score the comfort of the infants using the COMFORTneo score, which is validated for measuring objectively the (dis)comfort of a preterm infant [19]. Interrater reliability was assessed by Caljouw et al. [19], who found that the COMFORTneo score is reliable to measure distress in preterm infants. With a score $<14$, the infant's comfort is considered to be acceptable [19]. The comfort score before, during and after MIST of both groups were retrieved and noted. In our unit, interrater reliability between nurses of the COMFORTneo research group [19] and other NICU nurses was assessed in ten clinical situations, and nurses could measure comfort using the COMFORTneo score if they had achieved a Cohen's $\kappa>0.6$. Cohen's $\kappa$ measures the interrater agreement, where 0 means no agreement and 1 means total agreement [20].

Both COMFORTneo scores and basic characteristics (gestational age, gender and birth weight) were gathered, as well as complications of MIST and the administration of propofol. These complications included the need for nasal intermittent positive pressure ventilation (nIPPV), intubation, the occurrence of desaturation (oxygen saturation $<80 \%$ ), hypotension (mean $\mathrm{mm} \mathrm{Hg}$ be- 
Table 1. Results: comfort

\begin{tabular}{|c|c|c|c|}
\hline & $\begin{array}{l}\text { Sedated group } \\
(\mathrm{n}=23)\end{array}$ & $\begin{array}{l}\text { Nonsedated group } \\
(\mathrm{n}=15)\end{array}$ & $\mathrm{p}$ \\
\hline COMFORTneo score before MIST & $\begin{array}{l}\mathrm{n}=18 \\
11(9-15)\end{array}$ & $\begin{array}{l}\mathrm{n}=11 \\
10(8-12)\end{array}$ & n.s. \\
\hline COMFORTneo score during MIST & $\begin{array}{l}\mathrm{n}=17 \\
12(9-17)\end{array}$ & $\begin{array}{l}\mathrm{n}=10 \\
20(15-23)\end{array}$ & 0.002 \\
\hline COMFORTneo score $<14$ during MIST & $\begin{array}{l}\mathrm{n}=16 \\
9(56)\end{array}$ & $\begin{array}{l}\mathrm{n}=9 \\
1(11)\end{array}$ & 0.04 \\
\hline COMFORTneo score after MIST & $\begin{array}{l}\mathrm{n}=23 \\
10(8-12)\end{array}$ & $\begin{array}{l}\mathrm{n}=9 \\
9(8-10)\end{array}$ & n.s. \\
\hline
\end{tabular}

Data is presented as medians (IQR) for nonparametric data.

low gestational age) or bradycardia (heart rate $<80 \mathrm{bpm}$ ). The differences in heart rate between the interval before the MIST and during the MIST were also compared for the sedated and the nonsedated groups.

All study data were retrieved from digital medical charts (PDMS; MetaVision iMDsoft, Leiden, The Netherlands), a clinical information system designed especially for use in NICUs. In this system, each parameter is noted every minute.

This was a retrospective study and did not need to comply with the Dutch law on Medical Research in Humans; the Research Ethics Committee issued a statement of no objection.

\section{Statistical Analysis}

Due to the retrospective nature of this study, a convenience sample was used. No power calculation was performed because there was no data regarding sedation during MIST. Statistical analysis was performed using SPSS 22 (IBM SPSS Statistics). The parameters of both groups were tested for normality using Kolmogorov-Smirnov and Shapiro-Wilkinson. The groups were compared using Student's t test for parametric variables, the Mann-Whitney test for nonparametric comparisons for continuous variables and the $\chi^{2}$ test for categorical variables. Results are presented as means (SD) for normally distributed values or medians (IQR) for nonnormally distributed values. $\mathrm{p}<0.05$ was considered statistically significant. Reported $\mathrm{p}$ values are two-sided.

\section{Results}

During the 1-year period, 310 infants with a gestational age between 26 and $36+6$ weeks were admitted to the NICU. In 38 infants surfactant was given by MIST, of which 23 infants received propofol (online suppl. video 1; see www.karger.com/doi/10.1159/000443823 for all online suppl. material) and 15 infants were not sedated (online suppl. video 2) based on the discretion of the attending neonatologist. The reason given for prescribing propofol was expected discomfort. There were no significant differences in mean (SD) gestational age [sedation vs. no sedation; 29 (2) vs. 29 (3) weeks], birth weight [sedation vs. no sedation; $1,312(483)$ vs. $1,469(588) \mathrm{g}]$ and the percentage of males [sedation vs. no sedation; $61 \%(14 / 23)$ vs. $73 \%(11 / 15)$; n.s.]. The median (IQR) duration of the procedure did not significantly differ between the groups [sedation vs. no sedation; $2(2-4)$ vs. 3 (2-7) min; n.s.]. There was a significant positive correlation between both gestational age $(\mathrm{r}=0.419, \mathrm{p}<0.05)$ and postnatal age $(\mathrm{r}=$ $0.435, \mathrm{p}<0.05)$ and COMFORTneo score during the procedure.

\section{Comfort}

Surfactant was administered by MIST 38 times, in which comfort was scored before, during and after the procedure in $76 \%(29 / 38), 71 \%(27 / 38)$ and $71 \%(27 / 38)$ of the procedures, respectively. Both before and after MIST, the median (IQR) COMFORTneo score did not differ between the study groups, but the COMFORTneo score during the procedure was significantly lower in the sedated group when compared to the nonsedated group (table 1). The comfort score was significantly more often $<14$ in the sedated group during MIST (56 vs. $11 \%$; p < $0.05)$. There was a significant positive correlation between both gestational age $(\mathrm{r}=0.419, \mathrm{p}<0.05)$ and postnatal age $(\mathrm{r}=0.435, \mathrm{p}<0.05)$ and COMFORTneo score during the procedure. However, as previously mentioned the gestational age did not differ between the sedated and the nonsedated group.

\section{Complications}

The occurrence of complications could be retrieved from the digital medical chart for all patients. Bradycardia and hypotension occurred in a few infants, but these were 
Table 2. Results: complications

\begin{tabular}{llll}
\hline & $\begin{array}{l}\text { Sedated group } \\
(\mathrm{n}=23)\end{array}$ & $\begin{array}{l}\text { Nonsedated group } \\
(\mathrm{n}=15)\end{array}$ & $\mathrm{p}$ \\
\hline nIPPV during MIST & $23(100)$ & $5(33)$ & 0.000 \\
Intubation in the first 24 h after MIST & $6(26)$ & $2(13)$ & n.s. \\
Intubation need during MIST & $2(9)$ & $0(0)$ & n.s. \\
Duration of SpO 2 <0\% during MIST, min & $3(2-4)$ & $1(0-2)$ & 0.001 \\
Hypotension during MIST & $3 / 14(21)$ & $2 / 11(18)$ & n.s. \\
Bradycardia during MIST & $3(13)$ & $5(33)$ & n.s. \\
Heart rate before - during MIST, bpm & $-4(-10$ to -1$)$ & $-2(-7$ to 3) & n.s. \\
\hline
\end{tabular}

Data is presented as medians (IQR) for nonparametric data and as $\mathrm{n}(\%)$ for categorical data.

Table 3. Results: reasons for intubation

\begin{tabular}{llll}
\hline & $\begin{array}{l}\text { Sedated group } \\
(\mathrm{n}=8)\end{array}$ & $\begin{array}{l}\text { Nonsedated group } \\
(\mathrm{n}=2)\end{array}$ & $\mathrm{p}$ \\
\hline Trachea could not be catheterized & $2(25)$ & $0(0)$ & n.s. \\
Infant did not meet MIST criteria before procedure & $2(25)$ & $0(0)$ & n.s. \\
Apnea & $2(25)$ & $1(50)$ & n.s. \\
No improvement/increase $\mathrm{FiO}_{2}$ need & $2(25)$ & $1(50)$ & n.s. \\
\hline
\end{tabular}

Data is presented as $\mathrm{n}(\%)$ for categorical data.

not significantly different between the groups (table 2). There was no significant increase or decrease in heart rate during the procedure in both groups. The median (IQR) duration of oxygen desaturation of all infants $(<80 \%)$ was longer in the sedated group [3 (2-4) vs. $1(0-2) \mathrm{min}$; p < $0.01]$. All patients in the sedated group needed nIPPV temporarily due to apnea and saturation $<80 \%$ during MIST as compared to $33 \%$ in the nonsedated group ( $\mathrm{p}<$ 0.001 ; table 2$)$. Two infants (8\%) in the sedated group were intubated during MIST due to failure of the procedure because the trachea could not be catheterized, but this did not occur in the nonsedated group (n.s.). There was no significant difference in occurrence of intubations in the first $24 \mathrm{~h}$ after MIST between the two groups (table 2). The intubated infants had a mean (SD) gestational age of 28 (2) weeks and a birth weight of 1,109 (454) g. Reasons to intubate in the first $24 \mathrm{~h}$ after MIST were apnea in 3 cases, no improvement or an increase in $\mathrm{FiO}_{2}$ need in 3 cases and no adequate respiratory drive before the procedure with persistent apnea after the procedure in 2 cases (table 3 ).

\section{Discussion}

In this retrospective cohort study, we observed that infants receiving propofol had a higher level of comfort compared to the infants receiving no sedation before MIST. However, infants receiving propofol desaturated for a longer period, needed temporarily nIPPV more frequently during the procedure and, although this did not reach significance, more often infants were intubated during or within $24 \mathrm{~h}$ after MIST. All other complications (hypotension and bradycardia) were not different between the groups.

Administration of surfactant without intubation and mechanical ventilation, using procedures such as MIST, has recently received increased attention and many neonatal units have adopted the method $[4,7,9,21]$. There is, however, no consensus on whether the procedure should be performed with or without the use of premedication, which has been a hot topic for debate. This is the first study describing the comfort of preterm infants receiving MIST using objective measurements and the ef- 
fect of sedation versus no sedation. It is argued by Dargaville et al. [4] that MIST can generally be performed without creating discomfort in the infants; however, this was not objectively evaluated. There is consensus that an intubation procedure should be performed while the infant is adequately sedated $[10,11]$. Laryngoscopy can be painful and is associated with crying and increased changes in intracranial pressure when infants are awake $[10,12$, 13]. It could be reasoned that this also accounts for MIST as laryngoscopy is also performed.

Although propofol has been used for the INSURE method, its usage for MIST has not been described before [18]. Propofol is used because of its short-acting character and it is also used in our unit as sedation for endotracheal intubation. We have chosen to use a low dose of propofol for MIST to minimize the risk of apnea and hypotension. Propofol has an anxiolytic effect in low dosages, but it is not known whether propofol has analgesic effects or not [22]. Propofol is effective for obtaining hypnosis and muscle relaxation in endotracheal intubation [17, 18]. One of the complications of propofol is respiratory depression [18]. This study has shown that all infants receiving propofol needed nIPPV temporarily, compared to $33 \%$ of infants receiving no propofol. However, respiratory drive might be depressed by the use of propofol; of all sedated infants, $2 / 23$ infants (9\%) needed to be intubated during the procedure due to other reasons than respiratory depression, as the trachea could not be catheterized. To make solid conclusions about respiratory depression caused by propofol for MIST, a randomized controlled trial is warranted.

When high doses of propofol were used ( 3 and $6 \mathrm{mg} /$ $\mathrm{kg})$, hypotension was considered a significant complication during and within $1 \mathrm{~h}$ after intubation $[23,24]$. In contrast, other studies reported that hypotension did not occur when propofol $2.5 \mathrm{mg} / \mathrm{kg}$ was used [17, 25]. Interestingly, Welzing et al. [18] also noted a high incidence of hypotension even when a dosage of $1 \mathrm{mg} / \mathrm{kg}$ was used. However, our study does not confirm this as we did not observe more hypotension when we used this low dose compared to no sedation.

The MIST procedure has been recently introduced in our unit and it is possible that infants would be more comfortable in a center with extensive experience in the procedure. However, the MIST procedures in our study were performed by neonatologists who were well trained in endotracheal intubation and laryngoscopy. Also, there were no significant differences in duration of the procedure and the frequency of complications in the nonsedated group appeared to be low.
The decision for the use of propofol as premedication for MIST was left to the discretion of the attending neonatologist, and a selection bias could have occurred. The reason given by the caregivers for the decision to use propofol was expected discomfort. However, gestational age, birth weight and COMFORTneo score before the procedure were not different between the groups, which makes it less likely that these items influenced the decision of the caregiver to give sedation or not.

This was a small retrospective cohort study with a convenience sample. We already reached a large difference in comfort score in this small group, but it is possible that differences in complications would have reached significance in a larger group. Although we could not retrieve the comfort score in all infants, this was equally distributed among the study groups. In addition, comfort was scored by nurses who were not blinded to the treatment given, which could influence the COMFORTneo scores and cause observer bias.

In summary, we observed more comfort in preterm infants when they received a low dose of propofol ( $1 \mathrm{mg} /$ $\mathrm{kg}$ ) as premedication for MIST, but an increase in respiratory complications and nonsignificantly more intubations. However, we do not consider this study to be conclusive and a randomized controlled trial is warranted to determine whether the benefit of sedation in comfort outweighs the risks of complications.

\section{Disclosure Statement}

The authors reported no competing interests.

References

1 Wang L, Chen L, Li R, Zhao J, Wu X, Li X, et al: Efficacy of surfactant at different gestational ages for infants with respiratory distress syndrome. Int J Clin Exp Med 2015;8:1378313789.

2 Dunn MS, Kaempf J, de Klerk A, de Klerk R, Reilly M, Howard D, et al: Randomized trial comparing 3 approaches to the initial respiratory management of preterm neonates. Pediatrics 2011;128:e1069-e1076.

- 3 Morley CJ, Davis PG, Doyle LW, Brion LP, Hascoet JM, Carlin JB: Nasal CPAP or intubation at birth for very preterm infants. N Engl J Med 2008;358:700-708.

4 Dargaville PA, Aiyappan A, De Paoli AG, Kuschel CA, Kamlin CO, Carlin JB, et al: Minimally-invasive surfactant therapy in preterm infants on continuous positive airway pressure. Arch Dis Child Fetal Neonatal Ed 2013; 98:F122-F126.

Dekker/Lopriore/Rijken/Rijntjes-Jacobs/ Smits-Wintjens/te Pas 
5 Mokres LM, Parai K, Hilgendorff A, Ertsey R, Alvira CM, Rabinovitch M, et al: Prolonged mechanical ventilation with air induces apoptosis and causes failure of alveolar septation and angiogenesis in lungs of newborn mice. Am J Physiol Lung Cell Mol Physiol 2009; 298:L23-L35.

- 6 Kribs A, Härtel C, Kattner E, Vochem M, Küster H, Möller J, et al: Surfactant without intubation in preterm infants with respiratory distress: first multi-center data. Klin Padiatr 2010;222:13-17.

-7 Aguar M, Cernada M, Brugada M, Gimeno A, Vento M: Minimally invasive surfactant therapy with a gastric tube is as effective as the intubation, surfactant, and extubation technique in preterm babies. Acta Paediatr 2014; 103:e229-e233.

-8 Dargaville PA, Aiyappan A, Cornelius A, Williams C, De Paoli AG: Preliminary evaluation of a new technique of minimally invasive surfactant therapy. Arch Dis Child Fetal Neonatal Ed 2011;96:F243-F248.

-9 Göpel W, Kribs A, Ziegler A, Laux R, Hoehn T, Wieg C, et al: Avoidance of mechanical ventilation by surfactant treatment of spontaneous breathing preterm infants (AMV): an open-label, randomised, controlled trial. Lancet 2011;378:1627-1634.

10 Friesen RH, Honda AT, Thieme RE: Changes in anterior fontanel pressure in preterm neonates during tracheal intubation. Anesth Analg 1987;66:874-878.
Pokela ML, Koivisto M: Physiological changes, plasma beta-endorphin and cortisol responses to tracheal intubation in neonates. Acta Paediatr 1994;83:151-156.

12 Raju TN, Vidyasagar D, Torres C, Grundy D, Bennett EJ: Intracranial pressure during intubation and anesthesia in infants. J Pediatr 1980;96:860-862.

13 Stow PJ, McLeod ME, Burrows FA, Creighton RE: Anterior fontanelle pressure responses to tracheal intubation in the awake and anaesthetized infant. Br J Anaesth 1988;60:167170.

14 Kelly MA, Finer NN: Nasotracheal intubation in the neonate: physiologic responses and effects of atropine and pancuronium. J Pediatr 1984;105:303-309.

15 Marshall TA, Deeder R, Pai S, Berkowitz P, Austin TL: Physiologic changes associated with endotracheal intubation in preterm infants. Crit Care Med 1984;12:501-503.

16 Millar C, Bissonnette B: Awake intubation increases intracranial pressure without affecting cerebral blood flow velocity in infants. Can J Anaesth 1994;41:281-287.

17 Ghanta S, Abdel-Latif EA, Lui K, Ravindranathan H, Awad J, Oei J: Propofol compared with the morphine, atropine, and suxamethonium regimen as induction agents for neonatal endotracheal intubation: a randomized, controlled trial. Pediatrics 2007;119:e1248e1255.

$\checkmark 18$ Welzing L, Kribs A, Eifinger F, Huenseler C, Oberthuer A, Roth B: Propofol as an induction agent for endotracheal intubation can cause significant arterial hypotension in preterm infants. Pediatr Anesth 2010;20:605611.
19 Caljouw MAA, Kloos MAC, Olivier MY, Heemskerk IW, Pison WCR, Stigter GD, et al: Measurement of pain in premature infants with a gestational age between $28-37$ weeks: validation of the adapted COMFORT scale. J Neonatal Nurs 2007;13:13-18

20 Altman DG: Practical Statistics for Medical Research. New York, Chapman and Hall/ CRC Press, 1999.

21 More K, Sakhuja P, Shah PS: Minimally invasive surfactant administration in preterm infants. JAMA Pediatr 2014;168:901-908.

-22 Kotani Y, Shimazawa M, Yoshimura S, Iwama $\mathrm{T}$, Hara $\mathrm{H}$ : The experimental and clinical pharmacology of propofol, an anesthetic agent with neuroprotective properties. CNS Neurosci Ther 2008;14:95-106.

23 Vanderhaegen J, Naulaers G, Van Huffel S, Vanhole C, Allegaert K: Cerebral and systemic hemodynamic effects of intravenous bolus administration of propofol in neonates. Neonatology 2010;98:57-63.

24 Simons SHP, van der Lee R, Reiss IKM, van Weissenbruch MM: Clinical evaluation of propofol as sedative for endotracheal intubation in neonates. Acta Paediatr 2013; 102:e487-e492.

25 Nauta M, Onland W, De Jaegere A: Propofol as an induction agent for endotracheal intubation can cause significant arterial hypotension in preterm infants. Pediatr Anesth 2011; 21:699-712. 